\title{
POWER DOMINATION IN THE GENERALIZED PETERSEN GRAPHS ${ }^{1}$
}

\author{
Min ZHAO \\ College of Science \\ China Jiliang University \\ Hangzhou 310018, Zhejiang, P.R. China \\ e-mail: minzhao@126.com \\ ERFANG SHAN ${ }^{2}$ AND LIYING KANG \\ Department of Mathematics \\ Shanghai University \\ Shanghai 200444, P.R. China \\ e-mail: efshan@i.shu.edu.cn \\ lykang@shu.edu.cn
}

\begin{abstract}
The problem of monitoring an electric power system by placing as few measurement devices in the system can be formulated as a power dominating set problem in graph theory. The power domination number of a graph is the minimum cardinality of a power dominating set. $\mathrm{Xu}$ and Kang [On the power domination number of the generalized Petersen graphs, J. Comb. Optim. 22 (2011) 282-291] study the exact power domination number for the generalized Petersen graph $P(3 k, k)$, and propose the following problem: determine the power domination number for the generalized Petersen graph $P(4 k, k)$ or $P(c k, k)$. In this paper we give the power domination number for $P(4 k, k)$ and present a sharp upper bound on the power domination number for the generalized Petersen graph $P(c k, k)$.
\end{abstract}

Keywords: power domination, domination, generalized Petersen graph, electric power system.

2010 Mathematics Subject Classification: 05C69, 05C90.

\footnotetext{
${ }^{1}$ Research was partially supported by the ZJNSF of China (grant number LQ14A010014) and NSFC (No. 11971298).

${ }^{2}$ Corresponding author.
} 


\section{REFERENCES}

[1] R. Barrera and D. Ferrero, Power domination in cylinders, tori, and generalized Petersen graphs, Networks 58 (2011) 43-49.

doi:10.1002/net.20413

[2] A. Behzad, M. Behzad and C.E. Praeger, On the domination number of the generalized Petersen graphs, Discrete Math. 308 (2008) 603-610. doi:10.1016/j.disc.2007.03.024

[3] D.J. Brueni and L.S. Heath, The PMU placement problem, SIAM J. Discrete Math. 19 (2005) 744-761. doi:10.1137/S0895480103432556

[4] P. Dorbec, M. Mollard, S. Klavžar and S. Špacapan, Power domination in product graphs, SIAM J. Discrete Math. 22 (2008) 554-567. doi:10.1137/060661879

[5] J. Fox, R. Gera and P. Stănică, The independence number for the generalized Petersen graphs, Ars Combin. 103 (2012) 439-451.

[6] J. Guo, R. Niedermeier and D. Raible, Improved algorithms and complexity results for power domination in graphs, Lecture Notes in Comput. Sci. 3623 (2005) 172-184. doi:10.1007/11537311_16

[7] T.W. Haynes, S.M. Hedetniemi, S.T. Hedetniemi, and M.A. Henning, Domination in graphs applied to electric power networks, SIAM J. Discrete Math. 15 (2002) 519-529. doi:10.1137/S0895480100375831

[8] T.W. Haynes, S.T. Hedetniemi and P.J. Slater, Fundamentals of Domination in Graphs (Marcel Dekker, New York, 1998).

[9] W.K. Hon, C.S. Liu, S.L. Peng and C.Y. Tang, Power domination on block-cactus graphs, in: The 24th Workshop on Combinatorial Mathematics and Computation Theory (2007) 280-284.

[10] C.S. Liao and D.T. Lee, Power domination problem in graphs, Lecture Notes in Comput. Sci. 3595 (2005) 818-828. doi:10.1007/11533719_83

[11] C.S. Liao and D.T. Lee, Power domination in circular-arc graphs, Algorithmica 65 (2013) 443-466. doi:10.1007/s00453-011-9599-x

[12] K.J. Pai, J.M. Chang and Y.L. Wang, A simple algorithm for solving the power domination problem on grid graphs, in: The 24th Workshop on Combinatorial Mathematics and Computation Theory (2007) 256-260.

[13] Y.L. Wang and G.S. Huang, An Algorithm for Solving the Power Domination Problem on Honeycomb Meshes (Master Thesis, Department of Computer Science and Information Engineering, National Chi Nan University, 2009). 
[14] H.L. Wang, X.R. Xu, Y.S. Yang and K. Lü, On the distance pair domination of generalized Petersen graphs $P(n, 1)$ and $P(n, 2)$, J. Comb. Optim. 21 (2011) 481-496. doi:10.1007/s10878-009-9266-1

[15] G. Xu, L. Kang, E. Shan and M. Zhao, Power domination in block graphs, Theoret. Comput. Sci. 359 (2006) 299-305. doi:10.1016/j.tcs.2006.04.011

[16] G. Xu and L. Kang, On the power domination number of the generalized Petersen graphs, J. Comb. Optim. 22 (2011) 282-291. doi:10.1007/s10878-010-9293-y

[17] H. Yan, L. Kang and G. Xu, The exact domintion number of the generalized Petersen graphs, Discrete Math. 309 (2009) 2596-2607. doi:10.1016/j.disc.2008.04.026

[18] B. Zelinka, Domination in generalized Petersen graphs, Czechoslovak Math. J. 52 (2002) 11-16. doi:10.1023/A:1021759001873

[19] M. Zhao, L. Kang and G.J. Chang, Power domination in graphs, Discrete Math. 306 (2006) 1812-1816. doi:10.1016/j.disc.2006.03.037

Received 31 July 2017 Revised 26 February 2018 Accepted 26 February 2018 